\title{
Seed extracts of Gleditsia triacanthos: Functional properties evaluation and incorporation into galactomannan films
}

\author{
Miguel A. Cerqueira, Bartolomeu W.S. Souza, Joana T. Martins, José A. Teixeira, António A. Vicente * \\ IBB - Institute for Biotechnology and Bioengineering, Centre of Biological Engineering, Universidade do Minho, Campus de Gualtar, 4710-057 Braga, Portugal
}

\section{A R T I C L E I N F O}

\section{Article history:}

Received 18 February 2010

Accepted 8 June 2010

\section{Keywords:}

Edible films

Galactomannan

Phenolic

Antioxidant

\begin{abstract}
A B S T R A C T
In this work, three different extraction procedures were performed in Gleditsia triacanthos seeds in order to obtain extracts that were characterized in terms of the yield of extraction, total phenolic content and antioxidant properties. The extracts have been shown to contain considerable amounts of phenolic compounds (between 4.93 and $12.34 \mathrm{mg}_{\text {galicacid }}$ gextract $^{-}{ }^{1}$ ) and antioxidant activity between 18.77 and $71.59 \%$. Different concentrations of one of the extracts (extract presenting simultaneously the best values of total phenolic content, radical scavenging activity and the concentration of the compounds that caused a $50 \%$ inhibition of the radical scavenging activity) were incorporated into $G$. triacanthos galactomannan solutions and films were cast from these. A $2^{2}$ full factorial design was done to evaluate the effect of the galactomannan and extract concentrations in film properties. Galactomannan concentrations ranging from 0.5 to $1.5 \%$ and extract concentrations ranging from 0 to $1.0 \%$, were used and the evaluated film properties as: water vapour permeability, colour, total phenolic compounds content and antioxidant activity. This work has shown that $G$. triacanthos can be used not only as a source of galactomannan films suitable to incorporate antioxidant compounds for further application in the food industry but also as a source of the active compounds to be incorporated.
\end{abstract}

(c) 2010 Elsevier Ltd. All rights reserved.

\section{Introduction}

Nowadays there is an increasing interest in identifying antioxidant properties in products from natural sources to be used e.g. in food preservation or in health-enhancing foods. Edible films can provide additional protection for food, while being a fully biodegradable, environmental friendly packaging system. They can be used to improve food quality and prolong shelf-life of fresh products and they can be used to carry functional ingredients such as antioxidants, antimicrobials, nutrients, and flavours to further enhance food stability, quality, functionality and safety (Lin \& Zhao, 2007). In addition, there is a very strong interest in identifying antioxidant properties from products of natural sources in view of their application in food preservation: e.g., active substances such as plant extracts can be added, conferring e.g. antimicrobial and/or antioxidant properties to the foods (Lee, 2005).

Antioxidants can be incorporated into or coated onto food packaging materials to control the oxidation of fatty components and pigments, and can contribute to the quality preservation of foods; some antioxidants incorporated into plastic packaging materials may have the dual role of protecting the polymer as well as the packaged food from oxidation (Lee, 2005). The number of studies related with

\footnotetext{
* Corresponding author. Tel.: +351 253604 419; fax: +351 253678986 . E-mail address: avicente@deb.uminho.pt (A.A. Vicente).
}

residual sources of active compounds has been increased considerably driven by the high interest of the agro and food industry, and fostered by the increasing amount of information about the specific location of active compounds and their modification during processing (Demo, Petrakis, Kefalasa, \& Boskou, 1998; Jayaprakasha, Selvi, \& Sakariah, 2003; Xanthopoulou, Nomikos, Fragopoulou, \& Antonopoulou, 2009).

Many publications reported that seeds could be considered a valuable source of phenolics, showing to possess beneficial activities such as antioxidant, anti-carcinogenic, anti-microbial, anti-mutagenic and anti-inflamatory (Al-Farsi \& Lee, 2008). Recently, numerous reports have described antioxidants and compounds with radical scavenging activity present in fruits, seeds, vegetables, herbs and cereals extracts (Al-Farsi \& Lee, 2008; Majhenič, Škerget, \& Knez, 2007; Subhasree, Baskar, Keerthana, Susan, \& Rajasekaran, 2009).

The studies of natural antioxidants with edible films/coatings are increasing in the last years, a great number of works report protein based film as the principal material used but only a few use polysaccharide based films as the main material (Gómez-Estaca, Bravo, Gómez-Guillén, Alemán, \& Montero, 2009; Gómez-Estaca, Montero, Fernández-Martín, Alemán, \& Gómez-Guillén, 2009; Han, Hwang, Min, \& Krochta, 2008; Nuthong, Benjakul, \& Prodpran, 2009; Seydim \& Sarikus, 2006; Sivarooban, Hettiarachchy, \& Johnson, 2008). To our knowledge, no research has been done on galactomannan active films with antioxidant properties.

Galactomannans are present in the endosperm of numerous plants, particularly the Leguminosae, and they have several functions, 
e.g. reserve of carbohydrates. Galactomannans are polysaccharides built up of a $\beta$-(1-4)-D-mannan backbone with single D-galactose branches linked $\alpha-(1-6)$. Galactomannans can often be used in different forms for human consumption. Featuring different physicochemical properties, galactomannans are a versatile material used for many applications: they are excellent stiffeners and stabilizers of emulsions, and the absence of toxicity allows their use in the textile, pharmaceutical, biomedical, cosmetics and food industries (Srivastava \& Kapoor, 2005). Some works have already used galactomannans from commercial and non-traditional origins as a source for films and coatings production (Chen \& Nussinovitch, 2001; Cerqueira, Lima, Souza, et al., 2009; Cerqueira, Lima, Teixeira, Moreira, \& Vicente, 2009). Seed extracts from Gleditsia triacanthos have been used in the cosmetic industry by GreenTech S.A. and is commercially available as Gleditschia. The hydroglycolic extract of $G$. triacanthos, containing an alkaloid (triancanthine), galactomannans, flavonoids and tannins is used for hair protection and fixing and in capillary care applications (see, e.g., Chemidex, 2008).

Antimicrobial and antioxidant packaging systems containing natural active substances may have high potential for commercial food packaging applications. Consumers clearly prefer to obtain a better food safety of fresh products and minimally processed foods using this type of packaging systems. Most materials containing natural active agents are more effective when there is a direct contact of the packaging materials with the food product. For an effective introduction of new packaging systems into the market, careful design is required. Natural antimicrobials and antioxidants are usually costly, and therefore further development of package design using the minimum of active agents is desirable for practical applications (Lee, 2005).

The work presented here had three objectives: the first one was to evaluate the total phenolic content and antioxidant properties of ethanolic and water extracts from $G$. triacanthos seeds; the second one was to demonstrate whether galactomannan films are suitable to incorporate antioxidant compounds for further application in the food industry; and thirdly, to show how the main film properties can change with galactomannan and extract concentrations.

\section{Materials and methods}

\subsection{Reagents}

G. triacanthos seeds were collected in the Botanic Garden of Porto, Portugal, in November 2007. The Folin-Ciocalteau reagent (Panreac, Spain), $\mathrm{Na}_{2} \mathrm{CO}_{3}$ (Fluka, Germany) and gallic acid (Sigma, Germany) were used in the quantification of the total phenolic content. Antioxidant determinations were performed using 2,2-diphenyl-1picrylhydrazyl (Sigma, Germany), 2,6-Di-tert-butyl-4-methylphenol (BHT) (Fluka, Germany), 3-ter-Butyl-4-hydroxyanisole (BHA) (Fluka, Germany) and methanol P.A. (Riedel-de Haën, Germany). The reagents for film formulations were glycerol $87 \%$ (Panreac, Spain) and distilled water.

\subsection{Extraction from galactomannan and extracts recovery}

The polysaccharide extraction was performed as described in Cerqueira, Pinheiro, et al. (2009) with some changes in the pretreatment processes, as described below.

\subsubsection{Pre-treatment $A$}

In this process, the seeds were removed from the pods, cleaned and placed in a blender, where they were mechanically broken into a coarse size (ca. 0.2 to $0.5 \mathrm{~mm}$ length). Following this operation, they were suspended in ethanol (purity 99.8\%, Riedel-de Haën, Germany) in a proportion of $1: 3$ (seeds:ethanol) at $70{ }^{\circ} \mathrm{C}$ during $15 \mathrm{~min}$. The ethanol was decanted and the endosperm was manually separated from the germ and the hull. This ethanolic fraction was called extract A.1. Then distilled water was added in a proportion of $1: 5$ (endosperm:water) and the suspension was left to rest for approximately $24 \mathrm{~h}$. Then water, in a proportion of 1:10, (suspension:water) was added and mixed in a blender for $5 \mathrm{~min}$. In this case no water extraction was performed (as in pre-treatments B and C) and this fraction (A.2) was integrally transferred for the purification process (described in Section 2.2.3).

\subsubsection{Pre-treatment $B$}

Also here the seeds were removed from the pods, cleaned and placed in a blender, where they were mechanically milled (until a fine powder was obtained). All the milled seeds were suspended in ethanol (purity 99.8\%, Riedel-de Haën, Germany) in a proportion of $1: 3$ (seeds:ethanol) at $70{ }^{\circ} \mathrm{C}$ during $15 \mathrm{~min}$. The ethanol was decanted (B.1) and distilled water was added in a proportion of $1: 5$ (endosperm:water), and the suspension was left to rest for approximately $24 \mathrm{~h}$. The water left during $24 \mathrm{~h}$ was removed being called B.2. Then water, in a proportion of 1:15 (suspension:water) was added and mixed in a blender for $5 \mathrm{~min}$.

\subsubsection{Pre-treatment $C$}

Also here the seeds were removed from the pods, cleaned and placed in a blender, where they were mechanically milled (until a fine powder was obtained). All the milled seeds were suspended in ethanol (purity 99.8\%, Riedel-de Haën, Germany) in a proportion of $1: 3$ (seeds:ethanol) at $70^{\circ} \mathrm{C}$ during $6 \mathrm{~h}$ (using a soxhlet system). The ethanol was decanted (C.1 fraction) and distilled water was added in a proportion of 1:5 (endosperm:water), the suspension was left to rest for approximately $24 \mathrm{~h}$. The water left during $24 \mathrm{~h}$ was removed being called C.2. Then water, in a proportion of 1:15 (suspension:water) was added and mixed in a blender for $5 \mathrm{~min}$.

\subsection{Galactomannan purification}

All the purification processes were performed in the same way. The endosperm mixed in the blender at the end of each pre-treatment performed, was filtered through a nylon net followed by a centrifugation step at $3800 \mathrm{~g}$ (Sigma $4 \mathrm{~K}$, B. Braun, Germany) during $20 \mathrm{~min}$ at $20^{\circ} \mathrm{C}$. The precipitation of the galactomannan was achieved by adding the supernatant to ethanol (purity 99.8\%, Riedel-de Haën, Germany) at a ratio of $1: 2$. The ethanol was decanted and the precipitated galactomannan was lyophilized and kept in a dry place until further use. The ethanol decanted in this process was called extracts A.3, B.3 and C.3 depending of the pre-treatment used.

\subsection{Extract recovery}

All the extracts from the different extraction steps were filtered (GF/F, Whatman filter paper), and concentrated in a rotary evaporator at $60{ }^{\circ} \mathrm{C}$. The extracts were stored in the dark at $5{ }^{\circ} \mathrm{C}$ until further use.

\subsection{Determination of total phenolic content (TPC)}

The determination of TPC in extracts and films was done by a UV spectrophotometer (Varian-UV-VIS Spectrophotometer, Germany), based on a colorimetric oxidation/reduction reaction, as described by Skerget et al. (2005). The oxidizing reagent used was Folin-Ciocalteu reagent. To $0.5 \mathrm{ml}$ of diluted extract $(20 \mathrm{mg}$ of extract in $10 \mathrm{ml}$ distilled water) or film (20 mg of film in $10 \mathrm{ml}$ distilled water) a volume of $2.5 \mathrm{ml}$ Folin-Ciocalteu reagent (diluted 10 times with water) and $2 \mathrm{ml}$ of $\mathrm{Na}_{2} \mathrm{CO}_{3}\left(75 \mathrm{~g} \mathrm{~L}^{-1}\right)$ (Riedel-de Haën, Germany) were added. Absorbance was measured at $760 \mathrm{~nm}$ after $30 \mathrm{~min}$ incubation at $25^{\circ} \mathrm{C}$ and the results were expressed as $\mathrm{g}$ of gallic acid from the calibration curve previously carried out with this reagent. All experiments were carried out in triplicate. The total phenolic content 
was determined as gallic acid equivalents and values are expressed as mg of gallic acid per $g$ of extract.

\subsection{Antioxidant activity}

The DPPH-scavenging potential of the different extracts and films was measured, based on the scavenging ability of stable 1,1-diphenyl2-picrylhydrazyl (DPPH) radicals by G. triacanthos extracts. The ability of extracts to scavenge DPPH radicals was determined by the method of Blois (1958). Briefly, $1 \mathrm{ml}$ of methanolic solution of DPPH (1 mM) (Riedel-de Haën, Germany) was mixed with $1 \mathrm{ml}$ of extract solution (containing $0.5-5.0 \mathrm{mg} \mathrm{mL}^{-1}$ of dried extract) or film solution (containing $0.5-5.0 \mathrm{mg} \mathrm{mL}^{-1}$ of film). The mixture was then vortexed vigorously and left for $30 \mathrm{~min}$ at room temperature in the dark. The absorbance was measured at $517 \mathrm{~nm}$ (Varian-UV-VIS Spectrophotometer, Germany) and the activity was expressed as percentage DPPH-scavenging activity relative to the control, using the following equation:

$\%$ Radical scavenging activity $(R S A)=\left[\frac{\left(A_{\text {control }}-A_{\text {sample }}\right)}{A_{\text {control }}}\right] \cdot 100$

Where $A_{\text {control }}$ represents the absorbance value of the control sample and $A_{\text {sample represents the absorbance value of the analysed }}$ sample. The $\mathrm{IC}_{50}$ value was also calculated as the concentration of the compounds that caused a $50 \%$ inhibition of the radical scavenging activity $(R S A)$. All experiments were carried out in triplicate.

\subsection{Determination of polysaccharide yield and extracts yield}

The polysaccharide yield $(P Y)$ was determined at the end of the purification for an initial mass of $50 \mathrm{~g}$ seeds. $P Y$ represents the total yield of the extraction and purification processes and was calculated dividing the mass of lyophilized galactomannan $(\mathrm{ml})$ by the initial mass of the seeds $(\mathrm{mi})$, expressed as $\mathrm{g}$ of galactomannan per $100 \mathrm{~g}$ of seeds $(\% \mathrm{w} / \mathrm{w})$.

The extracts yield $(E Y)$ was determined at the end of each recovered process $p i$ (where $p$ is the pre-treatment used A, B and C, and $i$ is the number of process 1 (for process A), 2 (for process $\mathrm{B}$ ) and 3 (for process $\mathrm{C}$ )). $E Y_{p i}$ was calculated dividing the mass of the recovered extract $\left(\mathrm{m}_{\mathrm{re}}\right)$ by the initial mass of seeds $\left(\mathrm{m}_{\mathrm{i}}\right)$, being expressed as $\mathrm{g}$ of extract per $100 \mathrm{~g}$ of seeds $(\% \mathrm{w} / \mathrm{w})$.

\subsection{Film preparation}

The film formulations were based in a $2^{2}$ level factorial design with a centre point. Galactomannan concentrations of 0.5, 1.0 and $1.5 \%(\mathrm{w} / \mathrm{v})$ were used, together with extract concentrations of 0.0 , 0.5 and $1.0 \%(\mathrm{w} / \mathrm{v})$ (Table 1$)$. A concentration of $0.5 \%(\mathrm{w} / \mathrm{v})$ of glycerol was used in all films formulations. The concentrations were chosen based on preliminary experiments (data not shown) where it was determined that for galactomannan concentrations above $1.5 \%$

Table 1

Galactomannan and extract concentrations used in films formulation, and coded levels associated to factorial design. Values of thickness of the films.

\begin{tabular}{llll}
\hline Film & $\begin{array}{l}\text { Galactomannan concentration } \\
(\mathrm{w} / \mathrm{v})\end{array}$ & $\begin{array}{l}\text { Extract concentration } \\
(\mathrm{w} / \mathrm{v})\end{array}$ & $\begin{array}{l}\text { Thickness } \\
(\mathrm{mm})\end{array}$ \\
\hline GT1 & $0.5(-1)$ & $0.0(-1)$ & $0.045 \pm 0.001^{\mathrm{a}}$ \\
GT2 & $0.5(-1)$ & $1.0(+1)$ & $0.110 \pm 0.004^{\mathrm{b}}$ \\
GT3 & $1.5(+1)$ & $0.0(-1)$ & $0.052 \pm 0.002^{\mathrm{c}}$ \\
GT4 & $1.5(+1)$ & $1.0(+1)$ & $0.105 \pm 0.006^{\mathrm{b}}$ \\
GT5 & $1.0(0)$ & $0.5(0)$ & $0.089 \pm 0.012^{\mathrm{d}}$ \\
\hline
\end{tabular}

$\overline{\mathrm{a}-\mathrm{d}}$ Different superscript letters in the same column indicate a statistically significant difference (Tukey test $p<0.05$ ). $(\mathrm{w} / \mathrm{v})$ their dissolution was extremely difficult; also for glycerol, previous studies indicated that for values lower than $0.5 \%(\mathrm{w} / \mathrm{v})$ the film would be too brittle. The extract used in the film formulation was selected based on the results presented in Table 2; the choice was made taking into account the extract presenting simultaneously the best values of $T P C, R S A$ and $\mathrm{IC}_{50}$. The films were prepared by dissolving the lyophilized galactomannan in distilled water $\left(20^{\circ} \mathrm{C}\right)$. Each mixture of galactomannan and glycerol was stirred for $2 \mathrm{~h}$ at room temperature $\left(20^{\circ} \mathrm{C}\right)$ and the seeds extracts were added at the corresponding concentration; the obtained suspensions were homogenized with an Ultra-Turrax homogenizer (T 25, Ika-Werke) in two cycles of $1 \mathrm{~min}$ at $5000 \mathrm{rpm}$.

The films were prepared with a constant amount $(28 \mathrm{~mL})$ of solution which was cast onto a $9 \mathrm{~cm}$ diameter Petri plate. The films were dried in an oven at $35^{\circ} \mathrm{C}$ for $16 \mathrm{~h}$ and maintained at $20{ }^{\circ} \mathrm{C}$ and $0 \%$ $\mathrm{RH}$, until further use.

\subsection{Film thickness}

The film thickness was measured with a digital micrometer (No. 293-5, Mitutoyo, Japan). Five thickness measurements were taken on each testing sample in different, randomly chosen points. The mean values were used to calculate water vapour permeability (WVP) and are presented in Table 1.

\subsection{Water vapour permeability measurement (WVP)}

The measurement of water vapour permeability (WVP) was performed gravimetrically based on ASTM E96-92 method (Guillard, Broyart, Bonazzi, Guilbert, \& Gontard, 2003). The film was sealed on the top of a permeation cell containing distilled water $(100 \% \mathrm{RH}$; $2337 \mathrm{~Pa}$ vapour pressure at $20^{\circ} \mathrm{C}$ ), placed in a desiccator at $20^{\circ} \mathrm{C}$ and $0 \% \mathrm{RH}$ ( 0 Pa water vapour pressure) containing silica. The cells were weighed at intervals of $2 \mathrm{~h}$ during $10 \mathrm{~h}$. Steady-state and uniform water pressure conditions were assumed by keeping the air circulation constant outside the test cell by using a miniature fan inside the desiccator. The slope of weight loss versus time was obtained by linear regression. Three replicates were obtained for each sample.

\subsection{Colour and opacity}

The colour of the films was determined with a Minolta colorimeter (Cr 400; Minolta, Japan). A white standard colour plate $(Y=93.5$, $x=0.3114, y=0.3190)$ for the instruments' calibration was used as a background for colour measurements of the films, and the $L^{*}, a^{*}$ and $b^{*}$ values of each film were evaluated by reflectance measurements. In

Table 2

Polysaccharide yield $(P Y)$, extract yield $(E Y)$, total phenolic content $(T P C)$, radical scavenging activity $(R S A)$ and $\mathrm{IC}_{50}$ of the analysed extracts; $R S A$ and $\mathrm{IC}_{50}$ values for $\mathrm{BHT}$ and BHA are given for comparison.

\begin{tabular}{lllllc}
\hline Sample & $\begin{array}{l}P Y \\
(\%)\end{array}$ & $\begin{array}{l}E Y \\
(\%)\end{array}$ & $\begin{array}{l}R S A \\
(\%)\end{array}$ & $\begin{array}{l}\mathrm{IC}_{50} \\
\left(\mathrm{mg} \mathrm{mL}^{-1}\right)\end{array}$ & $\begin{array}{l}T P C \\
\left(\mathrm{mg}_{\text {galicacid }} \text { gextract }^{-1}\right)\end{array}$ \\
\hline A.1 & 24 & 0.04 & $18.77 \pm 3.22^{\mathrm{c}}$ & $13.31 \pm 0.67^{\mathrm{c}}$ & $6.13 \pm 0.69^{\mathrm{a}}$ \\
A.3 & & 0.07 & $71.59 \pm 3.60^{\mathrm{b}}$ & $1.40 \pm 0.37^{\mathrm{d}}$ & $10.79 \pm 0.99^{\mathrm{c}}$ \\
B.1 & 20 & 0.14 & $61.88 \pm 5.32^{\mathrm{a}}$ & $3.94 \pm 0.49^{\mathrm{ab}}$ & $4.93 \pm 0.42^{\mathrm{a}}$ \\
B.2 & & 0.02 & $70.03 \pm 4.29^{\mathrm{b}}$ & $3.40 \pm 0.31^{\mathrm{a}}$ & $10.7 \pm 0.96^{\mathrm{bc}}$ \\
B.3 & & 0.02 & $71.11 \pm 4.42^{\mathrm{b}}$ & $3.20 \pm 0.18^{\mathrm{a}}$ & $9.90 \pm 0.81^{\mathrm{b}}$ \\
C.1 & 17 & 0.05 & $62.11 \pm 1.98^{\mathrm{a}}$ & $4.17 \pm 0.32^{\mathrm{b}}$ & $5.86 \pm 0.56^{\mathrm{a}}$ \\
C.2 & & 0.06 & $70.99 \pm 0.48^{\mathrm{b}}$ & $3.48 \pm 0.13^{\mathrm{a}}$ & $12.34 \pm 1.51^{\mathrm{c}}$ \\
C.3 & & 0.07 & $66.77 \pm 5.10^{\mathrm{ab}}$ & $3.45 \pm 0.28^{\mathrm{a}}$ & $9.82 \pm 0.33^{\mathrm{b}}$ \\
BHT & & & $76.36 \pm 2.27^{\mathrm{d}}$ & $0.34 \pm 0.02^{\mathrm{e}}$ & $0.34 \pm 0.02^{\mathrm{e}}$ \\
BHA & & & $76.91 \pm 3.17^{\mathrm{d}}$ & $0.06 \pm 0.01^{\mathrm{f}}$ & $0.06 \pm 0.01^{\mathrm{f}}$ \\
\hline
\end{tabular}

$\overline{\mathrm{a}-\mathrm{f} \text { Different superscript letters in the same column indicate a statistically significant }}$ difference (Tukey test $p<0.05$ ). 
this system $L^{*}$ indicates the lightness (ranging from black to white), and the horizontal axes, indicated by $a^{*}$ and $b^{*}$, are the chromatic coordinates (ranging from $-a^{*}$ : greenness, $-b^{*}$ : blueness to $+a^{*}$ : redness, $+b^{*}$ yellowness). The values of $a$ and $b$ approach zero for neutral colours and increase as the colour becomes more chromatic and more saturated.

The opacity of a material is an indication of how much light passes through it: the higher the opacity, the lower the amount of light that can pass through the material. Generally, the opacity is calculated from reflectance measurements. The opacity of the samples was determined according to the Hunter lab method, as the relationship between the opacity of each sample on a black standard $\left(Y_{b}\right)$ and the opacity of each sample on a white standard $\left(Y_{w}\right)$ (Eq. (2)). The measurements were repeated three times for each film.

Opacity $=\frac{Y_{b}}{Y_{w}} \cdot 100$

\subsection{Scanning electron microscopy (SEM)}

The surface morphology of the films was examined using a scanning electron microscope (Nova NanoSEM 200, The Netherlands) with an accelerating voltage from 10 to $15 \mathrm{kV}$. Before analyses, all samples were mounted on aluminium stubs using carbon adhesive tape and sputter-coated with gold (thickness of about $10 \mathrm{~nm}$ ).

\subsection{Statistical analysis}

Data analyses were performed using Microsoft Windows Excel 2003 and Statistica software (release 7, edition 2004, Statsoft, Tulsa, OK, USA).

The influence of the incorporation of the seeds extracts and the increase of galactomannan concentrations in galactomannan films were studied using a factorial design of 2-levels with one centre point. The independent variables and their concentration range were: galactomannan concentration $\left(X_{1}\right)$ from 0.5 to $1.5 \%(\mathrm{w} / \mathrm{v})$ and extract concentrations $\left(X_{2}\right)$ from 0 to $1.0 \%(\mathrm{w} / \mathrm{v})$, where $Y$ represents the dependent variables: WVP, Opacity, TPC and RSA.

The experimental data were fitted to a multifactor model, represented by Eq. (3):

$Y=a+b \cdot X_{1}+c \cdot X_{2}+d \cdot X_{1} \cdot X_{2}$

The fitting accuracy of the model was evaluated by the calculation of the coefficient of determination $\left(R^{2}\right)$ and the accuracy factor $\left(A_{f}\right)$. The value of $R^{2}$, which gives the percentage of the variance of the data that is explained by the model, was calculated by:

$R^{2}=1-\frac{S S R}{S S D}$

where SSD is the variance times the degrees of freedom:

$S S D=\sum_{i=1}^{n}\left(y_{e}-\hat{y}_{e}\right)^{2}$

with $\hat{y}_{e}$ being the average of all experimental data points:

$\hat{y}_{e}=\frac{\sum_{i=1}^{n} y_{e}}{n}$

The higher the $R^{2}$ value, the better the model fits the experimental data (Neter, Kutner, Nachtsheim, \& Wasserman, 1996). The accuracy factor $\left(A_{f}\right)$ provides information on the fitting accuracy. The closer the $A_{f}$ value is to 1 , the better the accuracy (Ross, 1996). $A_{f}$ was calculated by:

$A_{f}=10 \cdot \frac{\frac{j=J}{j=1} \log \left(\frac{R_{\mathrm{pred}}}{R_{\mathrm{obs}}}\right)}{J} j=1,2,3, \ldots J=$ numberof observations

\section{Results and discussion}

\subsection{Extraction yields of galactomannans and extracts}

Table 2 presents the values from polysaccharide extraction yield $(P Y)$ showing that the pre-treatment can influence the final yield of the galactomannan extraction. Pre-treatment A (PTA) showed the highest value of PY (24\%), followed by pre-treatment B (PTB) (20\%) and pre-treatment C (PTC) (17\%). These differences may be explained by the fact that in PTA the seeds were only broken and not totally milled as in the other two pre-treatments. Further, the difference registered between the values of PY for PTB and PTC could be attributed to the $6 \mathrm{~h}$ of extraction used in PTC, when compared with the 15 min in PTB. The values of PY achieved with PTA are in good agreement with other results presented by Sciarini, Maldonado, Ribotta, Pérez, and Léon (2008) and by Cerqueira, Pinheiro, et al. (2009).

Extract yield results are also shown in Table 2, being B.1 the extract with the highest $E Y$ value (0.14\%). The combination of the milling with a lower time of extraction, in the first step, provided higher values of EY for PTB, but in the following steps (B.2 and B.3) the values were lower when compared with PTA and PTC. The fraction A.3 has the second highest value of $E Y$, as well as C.2 and C.3, which might be explained by the absence of the second extraction step. In this case, the water left during $24 \mathrm{~h}$ is used in the hydration of the galactomannan. The subsequent precipitation with ethanol thus includes the compounds than are not removed in step two as in the other treatments. Considering the total $E Y$ values, treatments B and C were the most efficient with a total value of $0.18 \%$, followed by treatment $A$ with a total value of $0.11 \%$. Not surprisingly, in those pretreatments where the milling of the seeds is one of the steps, the total $E Y$ was higher than in the pre-treatment where the seeds were only broken.

\subsection{Determination of the total phenolic content (TPC)}

The total phenolic content is given in Table 2. The extracts from the first step of the pre-treatments (A.1, B.1 and C.1) present the lowest values of TPC, with statistically significant difference $(p<0.05)$ when compared with TPC values of the other steps (Table 2 ), this being explained by the ethanolic extraction performed in this step. This indicates that the phenolic compounds present in G. triacanthos extract are mostly constituted by water soluble compounds. This fact is confirmed by the results for the extracts from step 2 (B.2 and C.2) that present the highest $(p<0.05)$ value of TPC. In this step the seeds were left in water during $24 \mathrm{~h}$. In PTA, the absence of step 2 makes step 3 an extraction using water followed by ethanol, which explains the higher values $(p<0.05)$ of TPC for extract A.3 when compared with A.1. Khokahar and Magnusdottir (2002) have reported water as the better solvent to the extraction of Zea polyphenols when compared with a mixture of $80 \%$ of methanol and $70 \%$ of ethanol. The obtained results are in agreement with the TPC values obtained from Alpinia zerumbet seeds that present values of $13.7 \pm 0.4 \mathrm{mg}$ galic acid/g (extract) for extractions with diethyl ether (Elzaawely, Xuan, Koyama, \& Tawata, 2007). However, they are lower than the TPC values obtained from guarana seeds that ranged between 119 and $186 \mathrm{mg}$ galicacid $\mathrm{g}_{\text {extract }}^{-1}$ (Majhenič et al., 2007). 


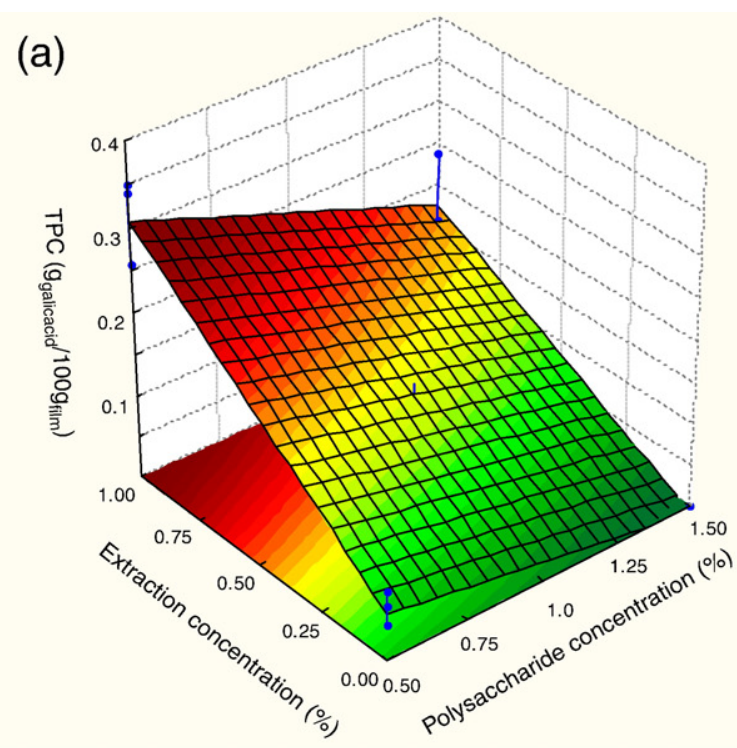

(b)

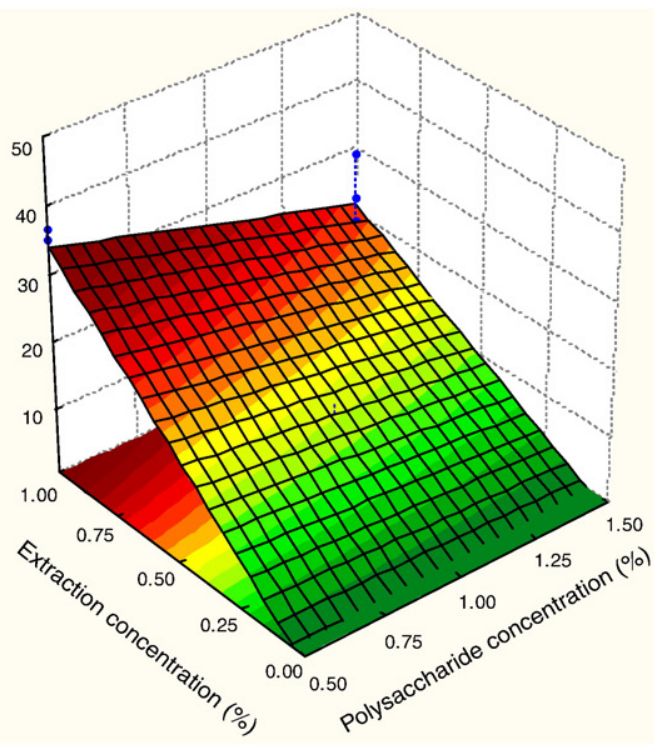

(c)

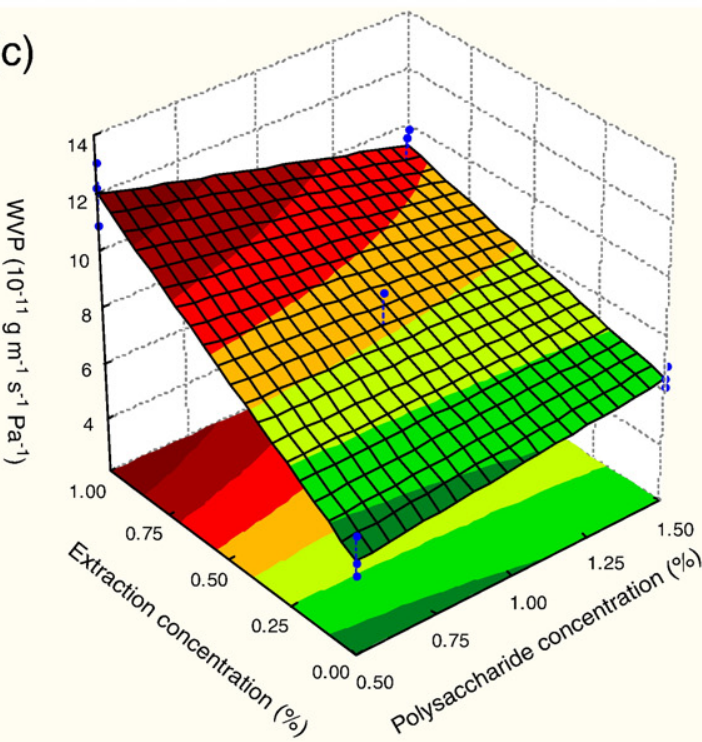

Fig. 1. Values of TPC (a), RSA (b) and WVP (c) in films as a function of both galactomannan and extract concentrations.

\subsection{Antioxidant activity}

The DPPH radical is widely used to evaluate the free-radical scavenging capacity of antioxidants (Zhenbao, Fei, Ling, Guanjun, \& Xiaolin, 2007); in this work, it is presented in terms of the radical scavenging activity $(R S A)$ and by $\mathrm{IC}_{50}$ that represent the concentration of the compounds that caused $50 \%$ of inhibition of the oxidation. Therefore, the higher the value of $R S A$ the lower will be the concentration necessary to cause $50 \%$ of inhibition ( $\mathrm{IC}_{50}$ ). Table 2 shows that the highest $(p<0.05)$ values of $R S A$ were achieved by the fractions A.3, B.2, B.3, C.2 and C.3, having the lowest value of $\mathrm{IC}_{50}$ found for the fraction A.3 $(p<0.05)$. All the fractions corresponding to the first step of the pre-treatments (A.1, B.1 and C.1) have the lowest values $(p<0.05)$ of $R S A$ and, consequently, the highest values of $\mathrm{IC}_{50}$ confirming, in the case of fraction A.1, that the milling of the seeds before ethanol boiling in the pre-treatment process allows a more efficient antioxidant extraction thus increasing the antioxidant activity of those extracts. However, between fractions B.1 and C.1 no statistical significant differences could be observed ( $p>0.05$ ), which leads to the conclusion that the time of extraction seems not to be an important parameter for antioxidant extraction. Fraction A.3 presents a significant antioxidant activity (and the lowest $\mathrm{IC}_{50}$ ) when compared with the other fractions $(p<0.05)$. This value is in agreement with the value of $\mathrm{IC}_{50}$ obtained for the water fraction from the methanolic extracts of Cassia tora $\mathrm{L}$. seeds, where a value of 0.77 for $\mathrm{IC}_{50}\left(\mathrm{mg} \mathrm{mL}^{-1}\right.$ ) was reported (Zhenbao et al., 2007). RSA values are in agreement with the values obtained by Majhenič et al. (2007) in guarana seeds, with the exception of fraction A.1, where the water and ethanolic extracts present $40 \%$ higher values. The obtained values to $\mathrm{IC}_{50}$ are also in good agreement with other types of extracts. Kil et al. (2009) presented values of $\mathrm{IC}_{50}$ that ranged between 4.0 and $129.0 \mathrm{mg} \mathrm{mL}^{-1}$ for 25 types of methanol sorghum extracts; and Subhasree et al. (2009) obtained values of $\mathrm{IC}_{50}$ that ranged between 0.085 and $0.435 \mathrm{mg} \mathrm{mL}^{-1}$ to methanolic extracts of four plant species (Trigonella foenum-graecum, Centella asiatica, Sauropus androgynus and Pisonia alba).

A relationship among the TPC, $R S A$ and $\mathrm{IC}_{50}$ is verified in Table 2, where higher values of TPC show a positive correlation with the antioxidant activity. The DPPH-scavenging activity of flavonoids and phenolic acids has been studied in other works. Da Silva, Souza, Matta, De Andrade, and Vidal (2006) showed that there is a positive correlation between the antioxidant activity of Brazilian commercial propolis extracts and their phenolic content. Hotta et al. (2002) proposed that the DPPH-scavenging activity is related, not only to its $\mathrm{H}$ donation ability, but also to the subsequent polymerisation reaction. Goupy, Dufour, Loonis, and Dangles (2003) proposed that the kinetics of the $\mathrm{H}$ transfer can be more important than the stoichiometry of the overall process.

The extract used in the film formulation was selected as the correspondent to fraction A.3 where the best values of TPC, RSA and $\mathrm{IC}_{50}\left(10.79 \mathrm{mg}_{\text {galicacid }} \mathrm{g}_{\text {extract }}^{-1}, 71.59 \%\right.$ and $1.40 \mathrm{mg} \mathrm{mL}^{-1}$, respectively) are obtained simultaneously.

\subsection{Physicochemical properties of galactomannan films}

\subsubsection{TPC and RSA}

The values of the total phenolic content (TPC) and radical scavenging activity (RSA) in galactomannan films containing the extract as a function of the extract and galactomannan concentrations are shown in Fig. 1(a) and (b), respectively. As expected, these results demonstrate that galactomannan films with the incorporation of the extract present in both cases improved TPC and RSA when compared with the films without extract, due to the entrapment of the extract compounds in the film. The most significant factor affecting TPC and $R S A$ in the studied films was the extract concentration $(p<0.05$, Table 2). The increase of TPC and RSA is generally proportional to the 
amount of extract added, with values that ranged between $0.00 \pm 0.00$ and $3.16 \pm 0.51 \mathrm{mg}_{\text {galicacid }} \mathrm{g}_{\text {film }}^{-1}$ to TPC and 0.00 and $36.17 \pm 0.89 \%$ to $R S A$. To films with $0.5 \%$ of galactomannan and $0 \%$ of extract (GT1) was detected a value $0.63 \pm 0.19 \mathrm{mg}_{\text {galicacid }} \mathrm{g}_{\text {film }}^{-1}$ to TPC. This value can be explained by the presence of phenolic compounds in the galactomannan polysaccharide that remain during the polysaccharide extraction process.

The fitting of the model equation (Table 3 ) to the experimental values led to good results, with values of $R^{2}$ above 0.90 and $A f$ close to 1 .

Fig. 2 shows scanning electron microscopy (SEM) photographs of the films with and without extract incorporation. The film without extract shows a more uniform and compact structure, otherwise the film with extract shows granular vesicles, presumably due to the extracts entrapped in the film. The vesicles exhibit spherical shapes with smooth surfaces that are apparently free of visible cracks and pores.

The obtained values of TPC and RSA for the galactomannan films showed that phenolic and antioxidant compounds added to the film forming solution can be later extracted from the galactomannan based films. In the future, the releasing characteristic of antioxidants incorporated in the films should be investigated.

\subsubsection{Water vapour permeability}

The water vapour permeability (WVP) is the most extensively studied property of edible films mainly because of the importance of the water in deteriorative reactions. Fig. 1(c) shows the changes of WVP with the concentration of galactomannan and extract. The WVP values ranged from $5.02 \pm 0.32 \times 10^{-11}$ (GT1) to $12.05 \pm$ $1.09 \times 10^{-11} \mathrm{~g} \mathrm{~m}^{-1} \mathrm{~s}^{-1} \mathrm{~Pa}^{-1}$ (GT2), being significantly different from each other $(p<0.05)$, and increasing with the increase of extract concentration (please see Table 4). The extract concentration and the interaction between the galactomannan and extract concentrations are the most significant factors that affect the WVP (Table 3). The

Table 3

Estimated values of the coefficients of Eq. (3), calculated for the regression performed on: the water vapour permeability (WVP), opacity, total phenolic content $(T P C)$ and radical scavenging activity $(R S A)$ values.

\begin{tabular}{|c|c|c|c|c|c|c|}
\hline Properties & $\begin{array}{l}\text { Independent } \\
\text { variable }\end{array}$ & $\begin{array}{l}\text { Regression } \\
\text { coefficient }\end{array}$ & $\begin{array}{l}\text { Standard } \\
\text { error }\end{array}$ & $\begin{array}{l}\text { Significance } \\
\text { level }(p)\end{array}$ & $R^{2}$ & $A f$ \\
\hline \multirow[t]{4}{*}{ WVP } & Constant & 4.7542 & 0.7590 & 0.0001 & 0.91 & 1.00 \\
\hline & $X_{1}$ & 1.1268 & 0.6858 & 0.1286 & & \\
\hline & $X_{2}$ & 8.5682 & 1.0843 & 0.0000 & & \\
\hline & $X_{1} X_{2}$ & -3.8637 & 0.9698 & 0.0021 & & \\
\hline \multirow[t]{4}{*}{ TPC } & Constant & 0.8631 & 0.3385 & 0.0270 & 0.92 & 0.92 \\
\hline & $X_{1}$ & -0.6348 & 0.3058 & 0.0621 & & \\
\hline & $X_{2}$ & 2.8728 & 0.4835 & 0.0001 & & \\
\hline & $X_{1} X_{2}$ & -0.6942 & 0.4325 & 0.1368 & & \\
\hline \multirow[t]{4}{*}{$R S A$} & Constant & -2.1236 & 4.9317 & 0.6751 & 0.90 & 0.83 \\
\hline & $X_{1}$ & 0.0000 & 4.4559 & 1.0000 & & \\
\hline & $X_{2}$ & 42.5490 & 7.0453 & 0.0001 & & \\
\hline & $X_{1} X_{2}$ & -12.7641 & 6.3015 & 0.0678 & & \\
\hline \multirow[t]{4}{*}{ Opacity } & Constant & 5.8675 & 2.1450 & 0.0194 & 0.84 & 0.98 \\
\hline & $X_{1}$ & 3.3776 & 1.9380 & 0.1092 & & \\
\hline & $X_{2}$ & 6.1494 & 3.0643 & 0.0700 & & \\
\hline & $X_{1} X_{2}$ & 2.9432 & 2.7408 & 0.3059 & & \\
\hline \multirow[t]{4}{*}{${ }^{*} L$} & Constant & 90.1641 & 1.9741 & 0.0000 & 0.95 & 0.99 \\
\hline & $X_{1}$ & -1.8472 & 1.7836 & 0.3226 & & \\
\hline & $X_{2}$ & -20.1325 & 2.8201 & 0.0000 & & \\
\hline & $X_{1} X_{2}$ & 1.3861 & 2.5224 & 0.5936 & & \\
\hline \multirow[t]{4}{*}{$* a$} & Constant & 4.7684 & 1.8182 & 0.0237 & 0.67 & 0.98 \\
\hline & $X_{1}$ & 0.1850 & 1.6427 & 0.9124 & & \\
\hline & $X_{2}$ & 4.6592 & 2.5974 & 0.1003 & & \\
\hline & $X_{1} X_{2}$ & 0.8183 & 2.3231 & 0.7313 & & \\
\hline \multirow[t]{4}{*}{${ }^{*} b$} & Constant & 12.3195 & 5.9981 & 0.0645 & 0.93 & 0.96 \\
\hline & $X_{1}$ & 3.4517 & 5.4193 & 0.5372 & & \\
\hline & $X_{2}$ & 57.3325 & 8.5687 & 0.0000 & & \\
\hline & $X_{1} X_{2}$ & -10.1239 & 7.6641 & 0.2133 & & \\
\hline
\end{tabular}

hydrophilic-hydrophobic ratio of the film constituents plays an important role in the water vapour transfer process (Gómez-Estaca et al., 2009). Seed extracts contain phenolic acids and flavonoids that contain polar compounds, therefore contributing to improve the hydrophilic properties of the films thus increasing the WVP. Also the hydrophobic properties of the extracts can contribute to extend intermolecular interactions of the structural matrix in the galactomannan film, allowing the water vapour to pass through the film. Fig. 2 shows that films without extract (Fig. 2a and c) present a compact structure showing a higher cohesiveness that the films with extract, contributing to the decrease of WVP. Similar results were obtained by Nuthong et al. (2009) with porcine plasma protein based films where the addition of tannic, caffeic and ferulic acids increase significantly the values of WVP.

The obtained values are in agreement with other published results for galactomannan films. Cerqueira, Lima, Souza, et al. (2009) present a WVP value of $3.24 \pm 0.23 \times 10^{-11} \mathrm{~g} \mathrm{~m}^{-1} \mathrm{~s}^{-1} \mathrm{~Pa}^{-1}$ for films with concentrations of $1.5 \%$ of galactomannan (G. triacanthos), $2.0 \%$ of glycerol and $0.5 \%$ of oil. Aydinli and Tutas (2000) obtained a value of $1.94 \times 10^{-11} \mathrm{~g} \mathrm{~m}^{-1} \mathrm{~s}^{-1} \mathrm{~Pa}^{-1}$ to films of $1 \%$ of galactomannan (Locust bean gum) and $0.3 \%$ of PEG 400 . The WVP values obtained in the present work are comparable to tuna-fish gelatine based films with murta extracts with values that ranged between 5.08 and $7.97 \times 10^{-11} \mathrm{~g} \mathrm{~m}^{-1} \mathrm{~s}^{-1} \mathrm{~Pa}^{-1}$ (Gómez-Guillén, Ihl, Bifani, Silva, \& Montero, 2007).

The fitting of the model equation (Table 3 ) to the experimental values has shown good results, with values of $R^{2}$ above 0.91 and $A f$ very close to 1 .

\subsubsection{Colour and opacity}

The opacity means a smaller transparency, important to control the incidence of light on food. Opacity values increase with the concentration of polysaccharide for all the studied films (Table 4). These results are in agreement with the results obtained by Cerqueira, Lima, Souza, et al. (2009) where the increase of the polysaccharide concentration in films with the same concentration of plasticizer and oil (both at $0.5 \%$ in weight) increase the values of opacity. Also, the addition of extract to the films leads to an increase of the opacity values, essentially due to the colour of extract added. Also GómezGuillén et al. (2007) showed that the incorporation of murta extracts to tuna-fish gelatin films decrease the transparency of the resulting films. This increase is related with enrichment of films with phenol compounds and in some extends with the interaction between the phenol and polysaccharide (Gómez-Estaca et al., 2009).

Table 4 shows the highest values $(p<0.05)$ of $a^{*}$ and $b^{*}$ for the films containing extracts when compared with the films without extracts. In fact, the films with extract present a darker and yellower appearance as evidenced by the lower value of $L^{*}$ and the higher values of $b^{*}$. Also Nuthong et al. (2009) for porcine plasma protein based films have shown a decreases in $L^{*}$ value and an increases in $a^{*}$ and $b^{*}$ values, when the tannic and caffeic acids were added.

The films with extract can have advantages due to their higher opacity, which can affect the light transmission through the film, having better light barrier properties which are advantageous when the light incidence is to be avoided. The extract concentration was the most significant factor $\left(X_{2}\right)$ contributing to opacity and to the colour coordinates, but its statistical significance was detected only in $L^{*}$ and $b^{*}(p<0.05$, Table 3$)$. The fitting of the model equation (Table 3$)$ to the experimental values has shown good results for $L^{*}$ and $b^{*}$ coordinates and not so good fitting to opacity and $a^{*}$ values. This is reflected in the values of $R^{2}$ and $A_{f}$.

\section{Conclusions}

Edible films can provide additional protection for food, while being a fully biodegradable, environmental friendly packaging system, 
(a)

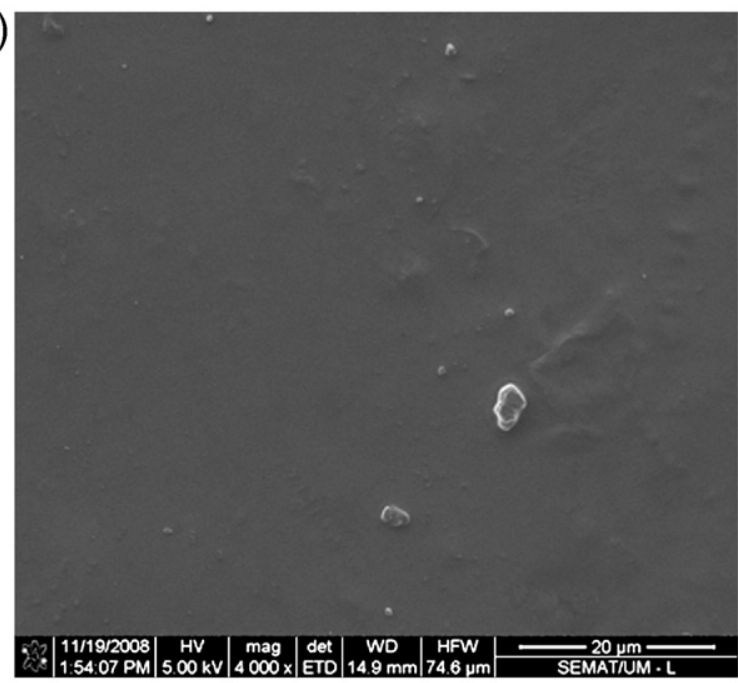

(b)

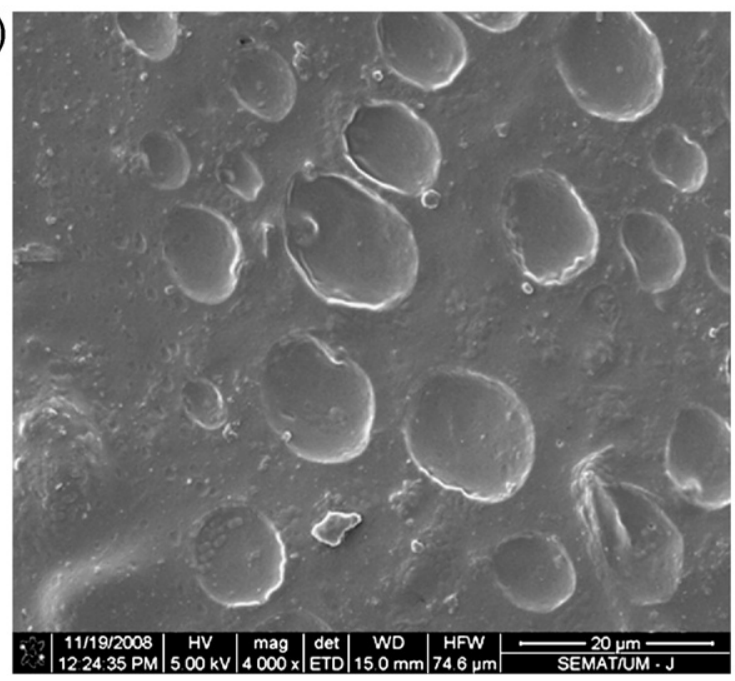

(c)

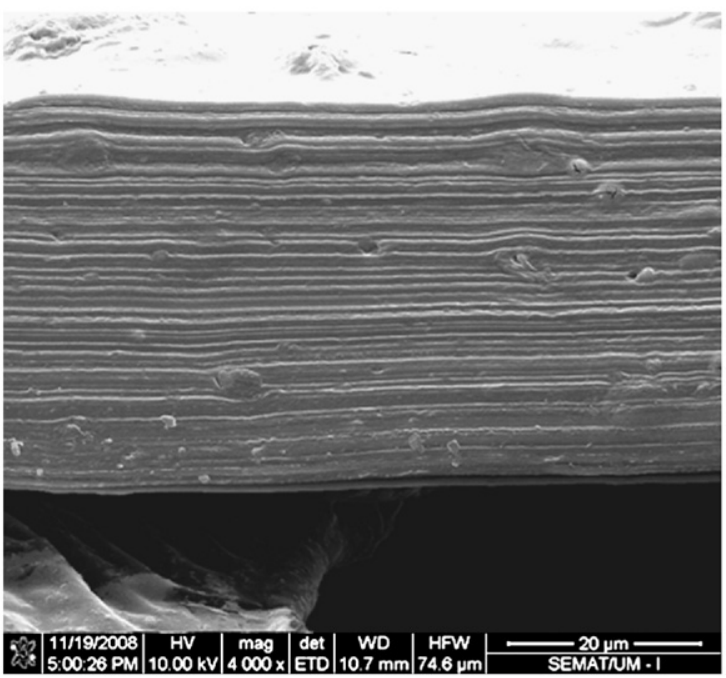

(d)

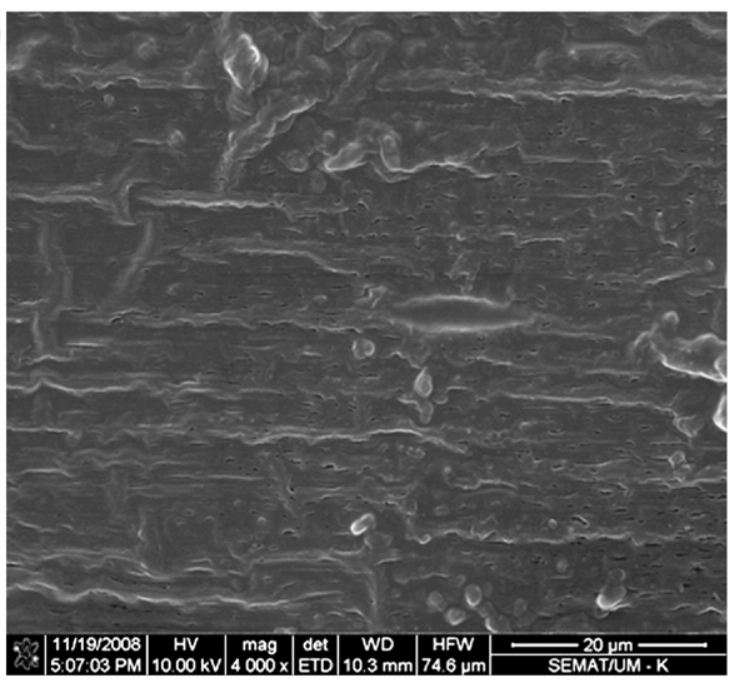

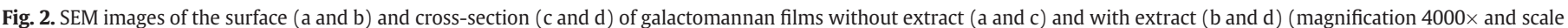
bar $20 \mu \mathrm{m})$.

especially if combined with antioxidant properties found in many natural sources, in view of food preservation. The results of this work have shown that $G$. triacanthos seed extracts can be used as a natural source of phenolic compounds and antioxidants; it has also shown that films produced from galactomannans of $G$. triacanthos are suitable to incorporate those antioxidant compounds for further application in the food industry, while also showing how the main film properties can change with galactomannan and extract concentrations.

Future research should be conducted to allow further identification of phenolic and antioxidant compounds present in seed extracts, and to evaluate their potential application in e.g. food packaging.

Table 4

Values of water vapour permeability (WVP), opacity, $L^{*}, a^{*}$ and $b^{*}$ of the films.

\begin{tabular}{crrlrl}
\hline Film & $\begin{array}{l}\text { WVP } \times 10^{-11} \\
\left(\mathrm{~g} \mathrm{~m}^{-1} \mathrm{~s}^{-1} \mathrm{~Pa}^{-1}\right)\end{array}$ & Opacity (\%) & $L^{*}$ & \multicolumn{1}{l}{${ }^{*}$} & $b^{*}$ \\
\hline GT1 & $5.02 \pm 0.32^{\mathrm{a}}$ & $4.35 \pm 0.57^{\mathrm{a}}$ & $88.62 \pm 1.29^{\mathrm{a}}$ & $5.66 \pm 0.19^{\mathrm{a}}$ & $11.49 \pm 1.56^{\mathrm{a}}$ \\
GT2 & $12.05 \pm 1.08^{\mathrm{b}}$ & $11.02 \pm 1.05^{\mathrm{b}}$ & $69.18 \pm 3.88^{\mathrm{b}}$ & $10.73 \pm 2.15^{\mathrm{b}}$ & $63.76 \pm 1.56^{\mathrm{b}}$ \\
GT3 & $6.54 \pm 0.37^{\mathrm{c}}$ & $4.94 \pm 0.09^{\mathrm{a}}$ & $86.77 \pm 2.11^{\mathrm{ac}}$ & $5.85 \pm 0.68^{\mathrm{a}}$ & $14.94 \pm 2.20^{\mathrm{a}}$ \\
GT4 & $9.31 \pm 0.67^{\mathrm{d}}$ & $20.09 \pm 1.68^{\mathrm{c}}$ & $68.72 \pm 0.28^{\mathrm{b}}$ & $11.73 \pm 0.15^{\mathrm{b}}$ & $57.09 \pm 4.12^{\mathrm{b}}$ \\
GT5 & $7.86 \pm 1.16^{\mathrm{c}}$ & $16.89 \pm 0.80^{\mathrm{d}}$ & $81.42 \pm 2.30^{\mathrm{c}}$ & $4.49 \pm 1.77^{\mathrm{a}}$ & $49.59 \pm 4.01^{\mathrm{c}}$ \\
\hline
\end{tabular}

$\overline{a-c}$ Different superscript letters in the same column indicate a statistically significant difference (Tukey test $p<0.05$ ).

\section{Acknowledgments}

M.A. Cerqueira and J.T. Martins are recipient of fellowships from the Fundação para a Ciência e Tecnologia (FCT, Portugal) (SFRH/BD/ $23897 / 2005$ and SFRH/BD/32566/2006, respectively) and the author B.W.S. Souza is the recipient of a fellowship from the Coordenação de Aperfeiçoamento de Pessoal de Nível Superior (CAPES, Brazil). We also acknowledge Dr. Edith Ariza from SEMAT/UM by the support in SEM analyses.

\section{References}

Al-Farsi, M. A., \& Lee, C. Y. (2008). Optimization of phenolics and dietary fibre extraction from date seeds. Food Chemistry, 108, 977-983.

Aydinli, M., \& Tutas, M. (2000). Water sorption and water vapour permeability properties of polysaccharides (locust bean gum) based edible films. LWT - Food Science and Technology, 33, 63-67.

Blois, M. S. (1958). Antioxidant determination by the use of a stable free radical. Nature, $181,1199-1200$.

Cerqueira, M. A., Lima, A. M. P., Souza, B. W. S., Teixeira, J. A., Moreira, R. A., \& Vicente, A. A. (2009). Functional polysaccharides as edible coatings for cheese. Journal Agriculture and Food Chemistry, 57(4), 1456-1462.

Cerqueira, M. A., Lima, A. M. P., Teixeira, J. A., Moreira, R. A., \& Vicente, A. A. (2009). Suitability from galactomannan in tropical fruit. Journal of Food Engineering, 94, $372-378$.

Cerqueira, M. A., Pinheiro, A. C., Souza, B. W. S., Lima, A. M. P., Riberio, C., Miranda, C., et al. (2009). Extraction, purification and characterization of galactomannans from non-traditional sources. Carbohydrate Polymers, 75, 408-414. 
Chemidex (2008). www.chemidex.com accessed in 16.12.2008.

Chen, S., \& Nussinovitch, A. (2001). Permeability and roughness determinations of waxhydrocolloid coatings, and their limitations in determining citrus fruit overall quality. Food Hydrocolloids, 15, 127-137.

Da Silva, J. F. M., Souza, M. C., Matta, S. R., De Andrade, M. R., \& Vidal, F. V. N. (2006). Correlation analysis between phenolic levels of Brazilian propolis extracts and their antimicrobial and antioxidant activities. Food Chemistry, 99, 431-435.

Demo, A., Petrakis, C., Kefalasa, P., \& Boskou, D. (1998). Nutrient antioxidants in some herbs and Mediterranean plant leaves. Food Research International, 31(5), $351-354$.

Elzaawely, A. A., Xuan, T. D., Koyama, H., \& Tawata, S. (2007). Antioxidant activity and contents of essential oil and phenolic compounds in flowers and seeds of Alpinia zerumbet (Pers.) B.L. Burtt. \& R.M. Sm. Food Chemistry, 104, 1648-1653.

Gómez-Estaca, J., Bravo, L., Gómez-Guillén, M. C., Alemán, A., \& Montero, P. (2009). Antioxidant properties of tuna-skin and bovine-hide gelatin induced by the addition of oregano and rosemary extracts. Food Chemistry, 112(1), 18-25.

Gómez-Estaca, J., Montero, P., Fernández-Martín, F., Alemán, A., \& Gómez-Guillén, M. C. (2009). Physical and chemical properties of tuna-skin and bovine-hide gelatin films with added aqueous oregano and rosemary extracts. Food Hydrocolloids, 23. $1334-1341$.

Gómez-Guillén, M. C., Ihl, M., Bifani, V., Silva, A., \& Montero, P. (2007). Edible films made from tuna-fish gelatine with antioxidant extracts of two different murta ecotypes leaves (Ugni molinae Turcz). Food Hydrocolloids, 21, 1133-1143.

Goupy, P., Dufour, C., Loonis, M., \& Dangles, O. (2003). Quantitative kinetic analysis of hydrogen transfer reactions from dietary polyphenols to the DPPH radical. Journal of Agricultural and Food Chemistry, 51(3), 615-622.

Guillard, V., Broyart, B., Bonazzi, C., Guilbert, S., \& Gontard, N. (2003). Preventing moisture transfer in a composite food using edible films: Experimental and mathematical study. Journal of food Science, 68(7), 2267-2277.

Han, J. H., Hwang, H. -M., Min, S., \& Krochta, J. M. (2008). Coating of peanuts with edible whey protein film containing $\alpha$-tocopherol and ascorbyl palmitate. Journal of Food Science, 73(8), E349-E355.

Hotta, H., Nagano, S., Ueda, M., Tsujino, Y., Koyama, J., \& Osakai, T. (2002). Higher radical scavenging activities of polyphenolic antioxidants can be ascribed to chemical reactions following their oxidation. Biochimica et Biophysica Acta-General Subjects, 1572(1), 123-132.

Jayaprakasha, G. K., Selvi, T., \& Sakariah, K. K. (2003). Antibacterial and antioxidant activities of grape (Vitis vinifera) seed extracts. Food Research International, 36, $117-122$.

Khokahar, S., \& Magnusdottir, S. G. (2002). Total phenol, cathechin and caffeine contents of teas commonly consumed in the United Kingdom. Journal of Agricultural and Food Chemistry, 50, 3713-3717.
Kil, H. Y., Seong, E. S., Ghimire, B. K., Chung, I. -M., Kwon, S. S., Goh, E. J., et al. (2009). Antioxidant and antimicrobial activities of crude sorghum extract. Food Chemistry, $115,1234-1239$.

Lee, D. S. (2005). In Jung Han (Ed.), Packaging containing natural antimicrobial or antioxidative agents. Innovations in Food Packaging. (pp. 108-122). Elsevier Science \& Technology Books.

Lin, D., \& Zhao, Y. (2007). Innovations in the development and application of edible coatings for fresh and minimally processed fruits and vegetables. Comprehensive Reviews in Food Science and Food Safety, 6(3), 60-75.

Majhenič, L., Škerget, M., \& Knez, Z. (2007). Antioxidant and antimicrobial activity of guarana seed extracts. Food Chemistry, 104, 1258-1268.

Neter, J., Kutner, M. H., Nachtsheim, C. J., \& Wasserman, W. (1996). Applied linear regression models (pp. 78-85). Chicago: The McGraw-Hill Co.

Nuthong, P., Benjakul, S., \& Prodpran, T. (2009). Effect of phenolic compounds on the properties of porcine plasma protein-based film. Food Hydrocolloids, 23, 736-741.

Ross, T. (1996). Indices for performance evaluation of predictive models in food microbiology. Journal of Applied Bacteriology, 81(5), 501-508.

Sciarini, L. S., Maldonado, F., Ribotta, P. D., Pérez, G. T., \& Léon, A. E. (2008). Chemical composition and functional properties of Gleditsia triacanthos gum. Food Hydrocolloids, 23(2), 306-313.

Seydim, A. C., \& Sarikus, G. (2006). Antimicrobial activity of whey protein based edible films incorporated with oregano, rosemary and garlic essential oils. Food Research International, 39, 639-644.

Sivarooban, T., Hettiarachchy, N. S., \& Johnson, M. G. (2008). Physical and antimicrobial properties of grape seed extract, nisin, and EDTA incorporated soy protein edible films. Food Research International, 41, 781-785.

Skerget, M., Kotnik, P., Hadolin, M., Rizner-Hras, A., Simonic, M., \& Knez, Z. (2005) Phenols, proanthocyanidins, flavones and flavonols in some plant materials and their antioxidant activities. Food Chemistry, 89, 191-198.

Srivastava, M., \& Kapoor, V. P. (2005). Seed galactomannans: An overview. Chemistry \& Biodiversity, 2. (pp. 295-317).

Subhasree, B., Baskar, R., Keerthana, R. L., Susan, R. L., \& Rajasekaran, P. (2009). Evaluation of antioxidant potential in selected green leafy vegetables.Food Chemistry, 115, 1213-1220 www.chemidex.com (Chemidex, 2008) accessed in 16.12.2008.

Xanthopoulou, M. N., Nomikos, T., Fragopoulou, E, \& Antonopoulou, S. (2009). Antioxidant and lipoxygenase inhibitory activities of pumpkin seed extracts. Food Research International, 42, 641-646.

Zhenbao, J., Fei, T., Ling, G., Guanjun, T., \& Xiaolin, D. (2007). Antioxidant properties of extracts from juemingzi (Cassia tora L.) evaluated in vitro. LWT - Food Science and Technology, 40, 1072-1077. 